\title{
Effects of DC Voltage Control Strategies of Voltage Response on Multi-Terminal HVDC Following a Disturbance
}

\author{
Francisco Gonzalez-Longatt \\ Faculty of Computing and Engineering, Coventry University \\ United Kingdom \\ fglongatt@ieee.org.ve
}

\begin{abstract}
The advantages of an HVDC grid are the possibility of transporting large amount of power over long distances and the possibility of trading energy among different ac systems. This paper shows the effects of de Voltage control strategy on the dynamic behavior of bus voltages at multi-terminal HVDC following a system disturbance. Two different de voltage control method are simulated in this paper: voltage margin method and voltage-droop method. Time-domain simulations on simple test system using DigSILENT ${ }^{\circledR}$ PowerFactory ${ }^{\mathrm{TM}}$ are used to evaluate the response of ac/dc bus voltage considering two disturbances: sudden load increase and sudden converter-station disconnection. Results demonstrate when two converters on the MTDC operate with de voltage droop characteristic; it appears a "collaborative scheme" for the dc voltage support, sharing the task of controlling the dc voltage. Simulation results demonstrate the voltage margin control is capable to survive a converter outage just if this converter is operating on constant power mode.
\end{abstract}

Index Terms--Multi-terminal HVDC, MTDC, Voltage Source Converters.

\section{INTRODUCTION}

The European Union (EU) and the G8 Heads of Government committed their countries in 2009 to an $80 \%$ reduction in Green House Gas emissions by 2050 [1]. International consensus to reach this target requires the EU to achieve a 'nearly zero-carbon power supply'. It will require an open market in electricity, underpinned by both upgraded and new trans-national transmission networks. This new transmission network will also support and balance variable sources of renewable energy generation to maintain security of supply and provide firm power across the EU [2].

Supergrid is the name of this future electricity system that will enable Europe to undertake a once-off transition to sustainability [1]. The electricity transmission system involved on Supergrid should be mainly based on direct current (dc), designed to facilitate large-scale sustainable power generation in remote areas for transmission to centers of consumption, one of whose fundamental attributes will be the enhancement of the market in electricity [3].

The North Sea has a vast amount of wind energy with largest energy per area densities located about 100-300 km of distance from shore [4]. High Voltage Direct Current (HVDC) transmission would be the more feasible solution at

\author{
Juan Manuel Roldan \\ Escuela Superior de Ingenieros, Universidad de Sevilla \\ Spain \\ jmroldan@us.es
}

such distances of sub sea transmission. Subsea ac transmission is usually more feasible if the distance is not more than about $50 \mathrm{~km}$, the so called 'break-even distance' for longer distances HVDC becomes the more economical solution [2].

There are two kind of HVDC transmission technology: Line Commutated Converter (LCC) based HVDC and Voltage Sourced Converter (VSC) based HVDC. LCCHVDC has several disadvantages: it cannot perform self restoration upon disconnection from the connected ac grid nor provide black start to the connected ac grid, in order to reverse the power transmitted; the dc voltage must be reversed. VSC-HVDC is superior to LCC-HVDC: risk of commutation failure is reduced using self-commutated switches, communication is not needed, it has black start compatibility and it has superior controllability: it is capable of independent control of active and reactive power flow.

Supergrid will probably grow in stages from connecting one offshore wind farm to one onshore grid toward linking several far offshore wind farms to multiple onshore grids [5]. It will include many HVDC cables to integrate all offshore wind power systems. When this kind of dc grid is built, connections must be made at the dc bus, multiple undersea cables and multiple converters at the same bus, a so-called multi-terminal HVDC (MTDC) configuration. For this, VSCHVDC is the most appropriate technology as it uses a common DC voltage and injects a variable current [6], [7].

The power injections in a dc grid are controlled by the converters. On a MTDC grid as Supergrid, the power flow into, or out of, each converter can be dynamically changed without any reconfiguration of the HVDC grid. Although Supergrid should allow the full control of active power on all converters, several control challenges arise from this condition [6]. If a dc node is suddenly disconnected, it will create an immediate imbalance on the DC grid that need to be removed by immediate control actions.

The purpose of this paper is to analyze the potential implications of the dc Voltage Control Strategy on the dynamic behavior of Multi-terminal HVDC following a Converter Outage, two dc voltage control strategies are explored in this paper: Voltage margin method and standard voltage droop. Section II describes the control strategies for MTDC operation. Section III shows voltage control strategies 
used in this paper. Section IV presents the simulations and results where the effects of a converter outage on the dynamic response are evaluated using time-domain simulations. Conclusions of this paper are presented on Section V.

\section{CONTROL STRATEGY FOR MTDC NETWORK OPERATION}

The control system for a MTDC is composed of two different layers of controllers [8], [9], [10], [11]: (i) terminal controllers and (ii) a master controller as illustrated in Fig. 1.

\begin{tabular}{|c|c|c|c|}
\hline \multicolumn{3}{|c|}{ Master Control } & $\begin{array}{c}\text { Supplementary } \\
\text { Control }\end{array}$ \\
\hline 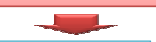 & 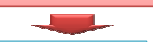 & $\square$ & + \\
\hline $\begin{array}{c}\text { Terminal } \\
\text { Controller } 1\end{array}$ & $\begin{array}{c}\text { Terminal } \\
\text { Controller } 2\end{array}$ & $\begin{array}{c}\text { Terminal } \\
\text { Controller } n\end{array}$ & $\begin{array}{l}\text { Outer Control } \\
\text { Inner Control }\end{array}$ \\
\hline$\sum^{v /=}$ & 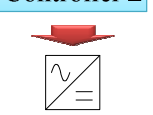 & 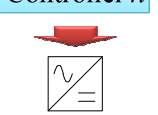 & $\frac{\text { Firing Control }}{2 /}$ Pulses \\
\hline VSC1 & VSC2 & $\mathrm{VSCn}$ & VSC \\
\hline
\end{tabular}

Fig. 1. Schematic representation of MTDC control system hierarchy.

The terminal controllers control the specific converters by calculating the PWM pulses for the converter bridges. Firing control is the lowest level on it and it acts very fast. Inner control, outer control and supplementary control are used for increasingly higher level functions, and have increasingly higher cycle times. The inner control or current control loop is designed to be much faster than the outer controllers. The outer controllers are the ones responsible for providing the current references signals for the inner current controller.

The terminal controllers determine the behaviour of the converter at the system bus. They are designed for the main functions for controlling [4], [12]: active power, reactive power, ac and the dc voltage. The master control optimizes the overall performance of the MTDC by regulating the $\mathrm{dc}$ side voltage. It is provided with the minimum set of functions necessary for coordinated operation of the terminals in the dc circuit, i.e. start and stop, minimization of losses, oscillation damping and power flow reversal, black start, ac frequency and ac voltage support.

\section{A. Current Controller}

The current controller loop is the inner part of the cascaded control strategy. It needs to be very fast as compared to the outer controllers so as to achieve control system stability. It is supplied current reference values from the outer controllers and $d q$ transformed currents from transducers.

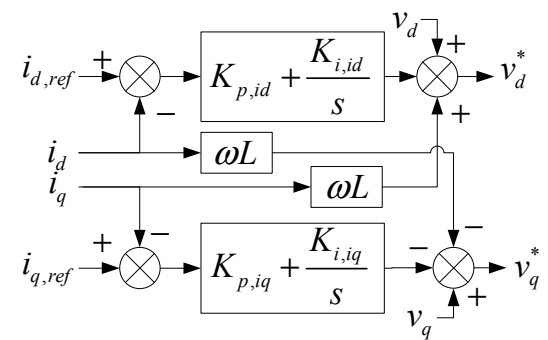

Fig. 2. Inner-Current Controller.

The objectives of the inner controller are to track the current reference values given by the outer controllers and to generate voltage reference values i.e. $u_{d}{ }^{*}$ and $u_{q}{ }^{*}$ fed to the controlled voltage source (see Fig. 2).

\section{B. Power Controller}

The active power controller is designed to regulate the active power $(P)$ exchanged at the common bus to match the given reference value $\left(P_{r e f}\right)$ by modifying $i_{d}{ }^{*}$. The output of the active power controller $\left(i_{d}{ }^{*}\right)$ is the reference input to the $d$ axis current controller of the inner current loop. In order to limit the magnitude of current in the VSC-HVDC to a maximum limit, the output of the active power controller is followed by a limiter function of $\pm i_{\max }$ limits, where: $i_{\max }=$ $i_{\text {rated }}$ (see Fig. 3)

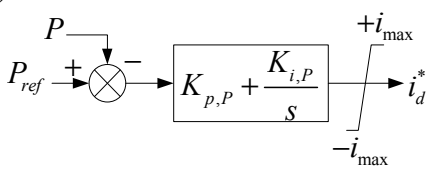

Fig. 3. Basic scheme for active power controller.

\section{Reactive Power Controller}

The objective of this controller is to govern the reactive power $(Q)$ exchanged at the common bus to match the given reference value $\left(Q_{r e f}\right)$ by modifying $i_{q}{ }^{*}$ (see Fig. 4 ).

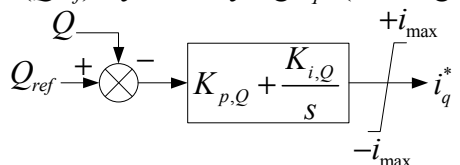

Fig. 4. Basic scheme for reactive power controller.

The output of the reactive power controller $\left(i_{q}^{*}\right)$ is the reference input for the reactive current controller of the inner current loop. $i_{q}{ }^{*}$ is limited to $\pm I_{q-\max }$ in such a way that the total converter current should not exceed the rated current $\left(I_{\max }=I_{\text {rated }}\right)$. This takes the assumption that that priority is given to transfer of active power. Hence:

$$
i_{q-\max }=\sqrt{I_{\max }^{2}-\left(i_{d}^{*}\right)^{2}}
$$

D. AC voltage controller

This controller is designed to regulate the amplitude of the ac voltage $\left(V_{a c}\right)$ at the common bus to be equal to the given reference value by modifying $i_{q}{ }^{*}$.

This implies that the controller governs the converter to generate an amount of reactive power so that the voltage at the common bus matches the given reference value $\left(V_{a c, r e f}\right)$ (see Fig. 5).

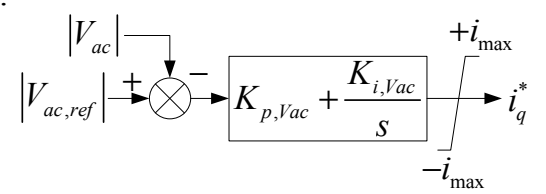

Fig. 5. Basic scheme for ac voltage controller.

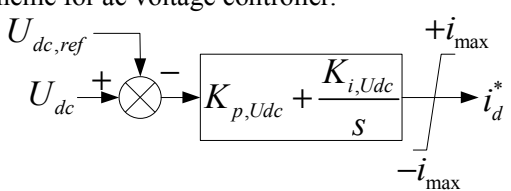

Fig. 6. Basic scheme for dc voltage controller.

\section{E. DC voltage controller}

The direct voltage controller regulates the active power exchanged at the common bus in order to maintain the direct voltage at the given reference, this objective is reached by modifying the value of $i_{d}{ }^{*}$ (see Fig. 6). 


\section{DC Voltage CONTROLler}

DC voltage control is certainly one of the most important tasks given to the VSC-HVDC stations inside a MTDC network. A well-controlled DC voltage on a MTDC system is a guarantee of the power balance between all the interconnected nodes. Considering the operational requirements for DC voltage on MTDC, the literature provides two control strategies which possibly can be applied in future transnational networks: (i) the direct voltage droop method and the (ii) voltage-margin method. These methods enable sharing of load among two or more dc voltage regulating terminals operating in parallel and provide controls in MTDC. Fig. 7 shows a general scheme for HVDC system considering only two converter substations.

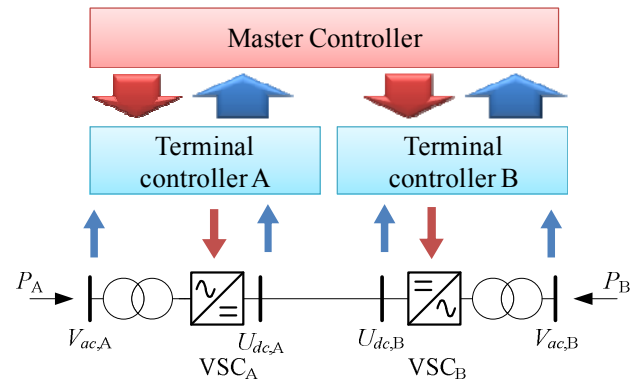

Fig. 7. General scheme for two converter stations HVDC system. VSC operates as inverter $\left(P_{i}<0\right)$ or rectifier $\left(P_{i}>0\right)$ depending in power direction.

\section{$F$. Principle of Voltage-Margin Method (VMM)}

The voltage margin is defined as the difference between the dc reference voltages of the two terminals [9]. Fig 8 shows the $U d c-P$ characteristics of both terminals at Terminal A, the intersection $U_{d c}-P$ of the characteristics of each terminal is the operating point "a".

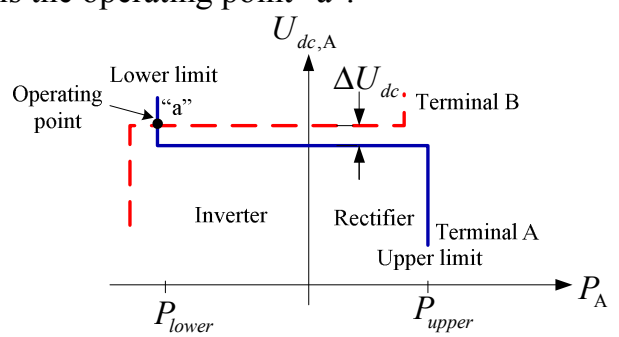

Fig. 8. $U_{d c}-P$ characteristic showing the operating point "a" in VMM for one terminal.

When the active power is to be transmitted from Terminal B to Terminal A $\left(P_{\mathrm{A}}<0, P_{\mathrm{B}}>0\right)$, the voltage margin $\left(\Delta U_{d c}\right)$ is subtracted from the dc reference voltage for Terminal A. Terminal B (rectifier) determines the dc system voltage and Terminal A (inverter) controls the active power $\left(P_{\mathrm{A}}\right)$ determined by the lower limit of the dc voltage regulator. The dc voltage controller tries to keep the dc voltage to the reference value $U_{d c \text {, ref }}$ by adjusting $P_{\mathrm{A}}$, until $P_{\mathrm{A}}$ reaches the upper limit or the lower limit (see Fig. 9).

The voltage margin method gives reliable way of controlling MTDC without the need for communication between terminals and is capable of keeping the steady state voltage with in preset limits even after load switching and disconnection of some converter terminals. But on the other hand, this method implies allocation of only one terminal at a time for the regulation of dc voltage and the other terminals do not experience significant change during changes in power flow of the dc network.

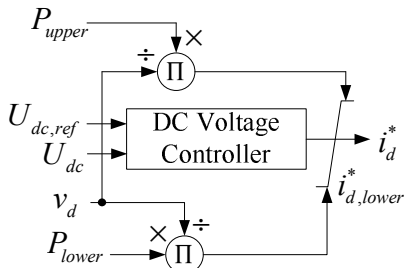

Fig. 9. Basic scheme for VMM controller with adjustable limits.

\section{G. Principle of Voltage-Droop Method (VDM)}

Frequency droop control is a well established method and the basis for stable operation in all ac grids. The systems frequency is used as a global measure for the instantaneous balance between power generation and demand [13]. The $d c$ voltage-droop method is a coordinated control to maintain a power balance and a desired power exchange in the MTDC. This control is a modification of the $V M M$ control where the horizontal line sections $\left(P_{\text {lower }}<P_{\mathrm{A}}<P_{\text {upper }}\right)$ of the $U_{d c}-P$ characteristic curves is replaced by a line with small slope $\left(m_{c}\right)$ [14]. The dc voltage-droop, $m_{c}$, indicates the degree of compensation of power unbalance in the dc grid at a cost of reduction in the dc bus voltage. This principle of $V M M$ control is shown in Fig. 10.

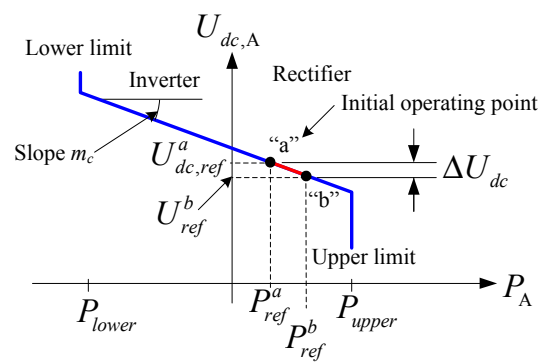

Fig. 10. $U_{d c}-P$ characteristic showing the operating point "a" in VMM for one terminal.

When $U_{d c, A}$ drops (e.g. due to large withdrawal of power someplace else in the dc network, operation point moves from "a" to "b") the slack converter station $\left(\mathrm{VSC}_{\mathrm{A}}\right)$ will increase the active power injection in the dc grid $P_{\mathrm{A}}$ until a new equilibrium point $\left(U_{d c, \text { ref }}^{b}, P_{A, r e f}^{b}\right)$, at a lower dc voltage, is reached $\left(U_{d c, r e f}^{b}=U_{d c, r e f}^{a}-\Delta U_{d c}\right)$.

The use of a proportional dc voltage-controller allows multiple converters to regulate the voltage at the same time and the concept of distributed slack bus is possible.

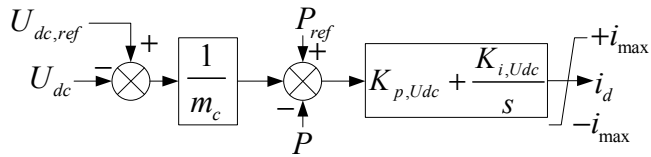

Fig. 11. Voltage droop controller.

Fig. 11 shows how is implemented the droop characteristic based on the power active controller. When voltage droop control is used in the absence of a PI controller, the voltage controller's active power $P$ will change when the value of the dc bus voltage changes. 


\section{Simulation AND Results}

In this paper, the dynamic behavior of a MTDC system following to a converter outage is analyzed considering two dc voltage control strategies: VMM and standard VDM. The dynamic behavior of ac/dc Test System is analyzed based on time-domain simulations. DIgSILENT ${ }^{\circledR}$ PowerFactory $^{\mathrm{TM}}$ $\mathrm{v} 14.0 .525 .1[16]$ is used to perform the simulations, the model of all controllers are developed using DIgSILENT Simulation Language (DSL). The steady state conditions for ac/dc network considering the dc voltage controller are calculated using a MATLAB ${ }^{\circledR}$ [17] program developed by the authors. All simulations are performed using a personal computer based on Intel ${ }^{\circledR}$, Core $^{\mathrm{TM}}$ i7 $\mathrm{CPU} 2.0 \mathrm{GHz}, 8 \mathrm{~GB}$ RAM with Windows 7 Home Edition 64-bit operating system.

Two different cases are discussed in this section. Case I: The effect of sudden load increases on power flows and transient response in the ac/dc Test System, Case II: The effects of a converter outage on the dynamic response are also analyzed. In both case two different control strategies mentioned above are compared.

\section{A. $\quad$ Test System}

The test network used in this paper is the classical 5-bus test network which is taken from G.W. Stagg \& A.H. ElAbiad [15] and is depicted in Fig. 12.

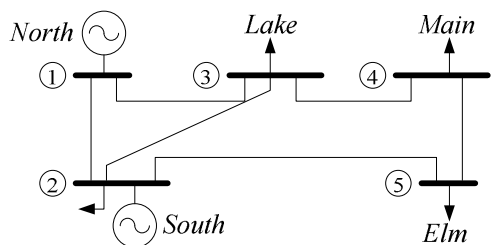

Fig. 12. AC Test System: of Stagg and El-Abiad [15].

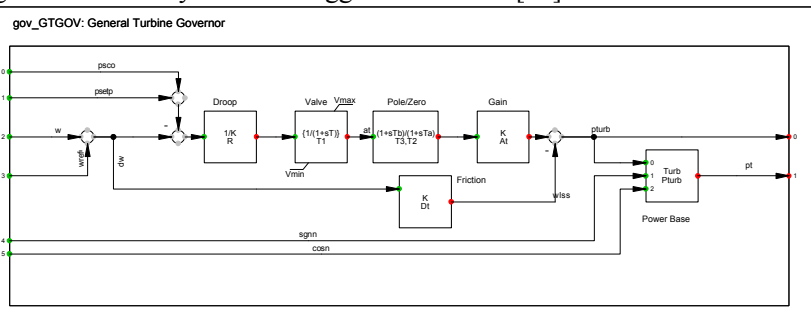

Fig. 13. Model of General Turbine Governor.

This system consists of 2-generator, 5-bus, 4-load, and 6transmission lines. The system has a total generation of 175.98 MW and a total load of $165 \mathrm{MW}$.

Since there are no dynamic data available for this test system, author uses typical values for generators based on its size, all generators are equipped with primary frequency control, automatic voltage regulator (AVR). Fig. 13 and 14, shows the general steam turbine used as governor for all synchronous power plants and a version on IEEE Type I excitation system is used as AVR [18].

Fig 15 shows a 3-node VSC MTDC network with is connected to the ac test system.

The converter at bus 3 (VSC37) is chosen as dc slack bus, thereby controlling the voltage on the dc network. This converter station is also used to control the voltage at bus 3 and it is the main target to evaluate two different dc voltage control strategies. The other converter stations (VSC26 and VSC58) are directly controlling their reactive power injections (constant $Q$-mode). Data on the converter station phase reactors and line resistances are obtained from [19], [20].

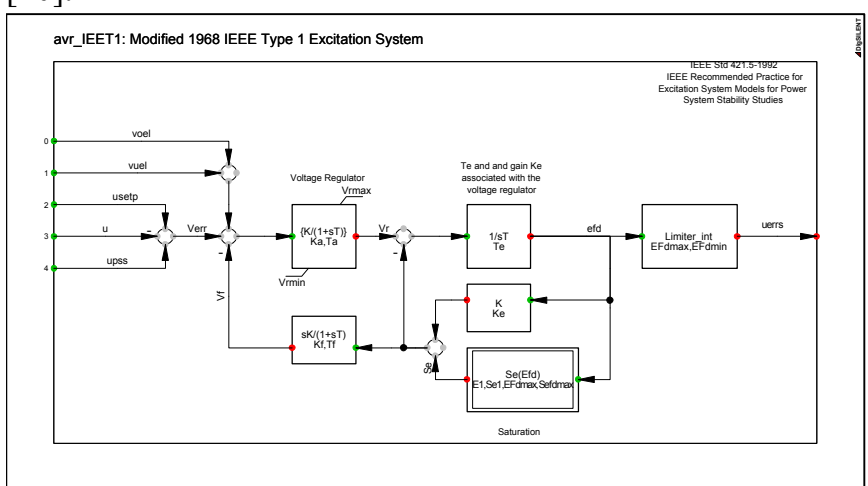

Fig. 14. Model of General AVR.

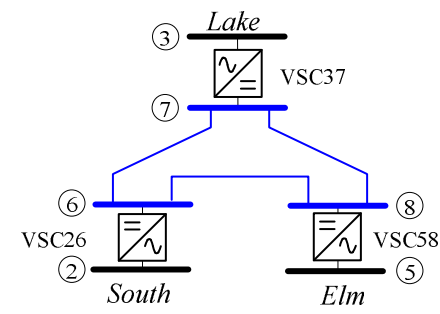

Fig. 1. DC Test System: VSC MTDC system.

B. Pre-Disturbance Steady-State

There is several software for the power systems analysis deal with power flows considering HVDC systems: DIgSILENT $^{\circledR} \quad$ PowerFactory [16], PSCAD $^{\circledR} \quad$ [21], CYMFLOW [22], MATLAB ${ }^{\circledR}$ SimPower Systems [23], etc. However, new DC voltage control methods are not included in most of them. In order to calculate the pre-disturbance steady state of the ac/dc Test system a MATLAB ${ }^{\circledR}$ [17] version 7.12.0.635 (R2011a 64-bit) program (m-file) is developed by author for this very specific purpose. Results of this ac/dc load flow are used to set-up steady-state of DIgSILENT $^{\circledR}$ PowerFactory ${ }^{\mathrm{TM}}$ and reach and smooth start-up for dynamic simulations.

An sequential solution algorithm is used for the ac/dc power flow solution, more details can be found on [24]. This algorithm is integrated with the aid of the ac power flow program Power System Toolbox (PST) [25], an open-source MATLAB $^{\circledR}$ toolbox. Fig. 2 and 17 show the results of the steady-state power flow for normal operation, prior disturbance for ac and dc Test System respectively. These results are used as input to provide the same steady-state operation point for all the dynamic simulations. The converter at bus 3 (VSC37) is chosen as DC slack bus, $U_{d c, 7}=1.00$ p.u, for both control method the same voltage is assumed constant. Converter stations VSC26 and VSC58 are operating on P-Q control mode: $P_{2}=-60 \mathrm{MW}, Q_{2}=40 \mathrm{MVAR}$ (rectifier mode) and $P_{5}=+35 \mathrm{MW}, Q_{5}=5 \mathrm{MVAr}$ (inverter mode). 


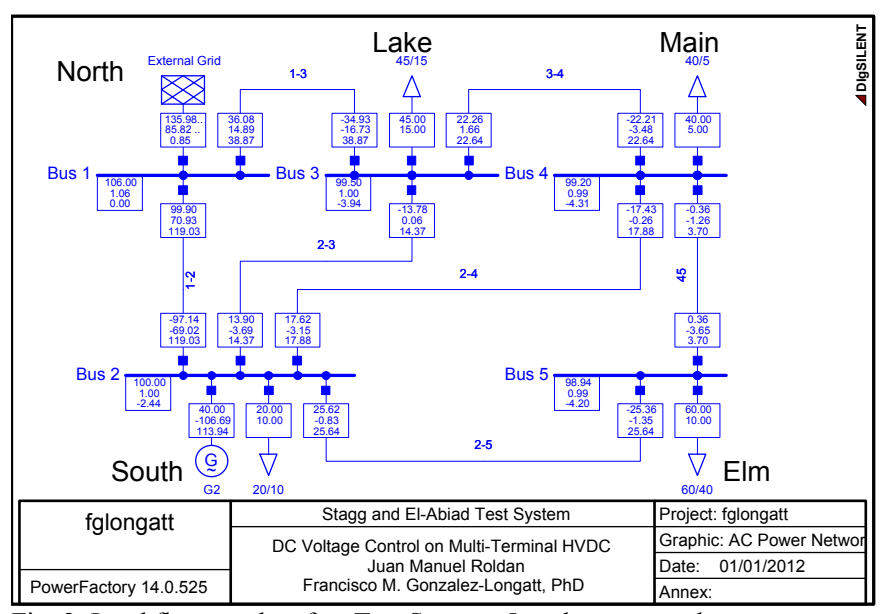

Fig. 2. Load flow results of ac Test System: 5-node ac network.

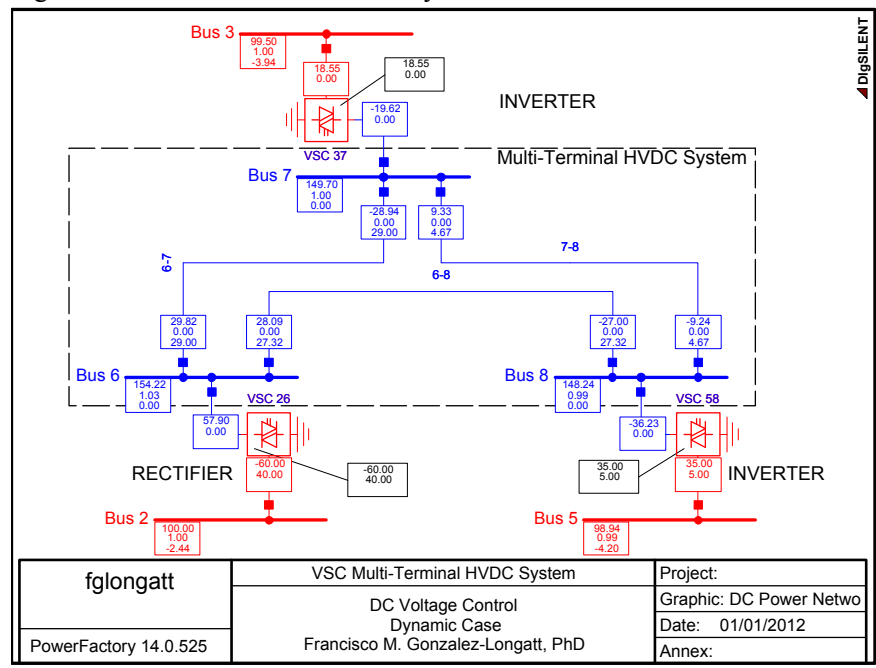

Fig. 3. Load flow results of DC Test System: 3-node VSC-MTDC system.

C. Controllers Implementation

The dynamic performance of ac/dc test system is evaluated using time domain simulation obtained from DIgSILENT ${ }^{\circledR}$ PowerFactory $^{\mathrm{TM}}$. DIgSILENT Simulation Language (DSL) is used to create all models of the controllers defined on Section II and III for the MTDC transmission system.

D. Case I: Sudden Load Increase

A sudden load increase of $40 \mathrm{MW}$ on bus 3 is considered in this scenario. The dynamic behavior of de voltage at bus 6 and ac bus 5 is depicted on Fig. 18 and 19.

The blue line shows the bus voltage's response with only one voltage controller operating, voltage margin method. The red line represents the dynamic response when a voltage droop controller $\left(m_{c}=-0.1\right)$ is operating on converter station VSC26.

The transient over-voltages and under-voltages are reduced as expected using the droop control. The slopes of the voltage-droop controller considered in this simulation are $1 / m_{c}=-10.0,-8.0,-2.0$ p.u. for converters VSC26, VSC37, VSC58 respectively.

\section{E. Case II: One Converter Outage}

This simulation results are used to investigate the effect of a distributed voltage droop control on bus 2 (VSC26). Two different values of voltage-droop slope $\left(m_{c}\right)$ have been tested.
Result shows the dynamic response of bus voltages is clearly influenced by the voltage-droop characteristic.

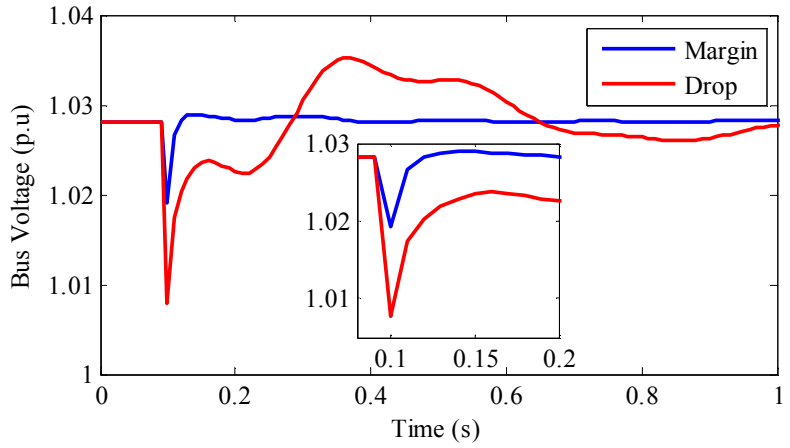

Fig. 18. Dynamic response of $U_{d c}$ at Bus 6 after sudden load increase event considering two control strategies: voltage margin (blue) and droop (red). Case I.

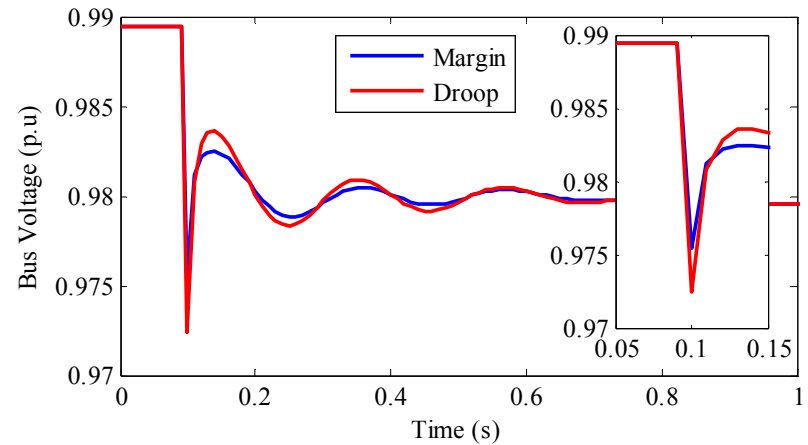

Fig. 19. Dynamic response of $U_{d c}$ at Bus 5 after sudden load increase event considering two control strategies: voltage margin (blue) and droop (red). Case I.

Fig. 20 shows response of bus voltage at bus 6 considering a perturbation based on the outage of VSC58. As shown, an incorrect selection slope value may causes transient responses with greater over-voltages on the $\mathrm{dc}$ bus (Droop B, green line). However, if voltage-droop slope is correctly selected it can assist the main the voltage at slack bus 3 and the system can handling transients caused by one converter station outage.

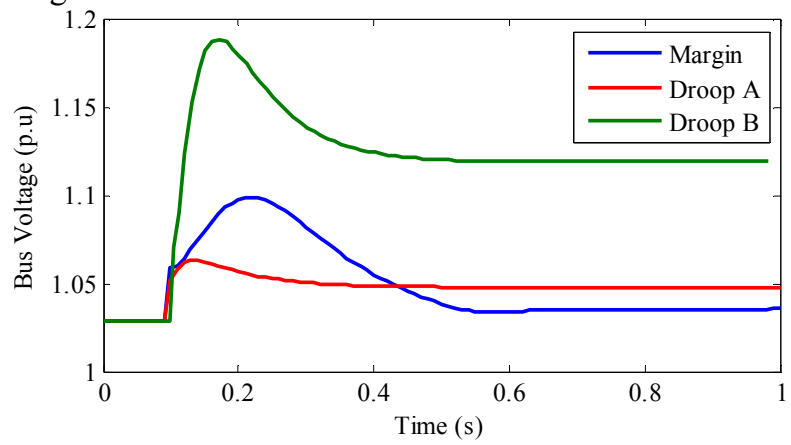

Fig. 20. Bus 6, DC voltage transient with margin and droop control strategies.

The ac voltage transient response is not significantly influenced by voltage droop slope as shown on Fig. 21.

When the droop control is implemented in a larger dc network, the contribution of each converter to the dc voltage control can be adapted by modifying its droop characteristic. The values of the voltage droop slope used in this simulation are shown on Table I. 


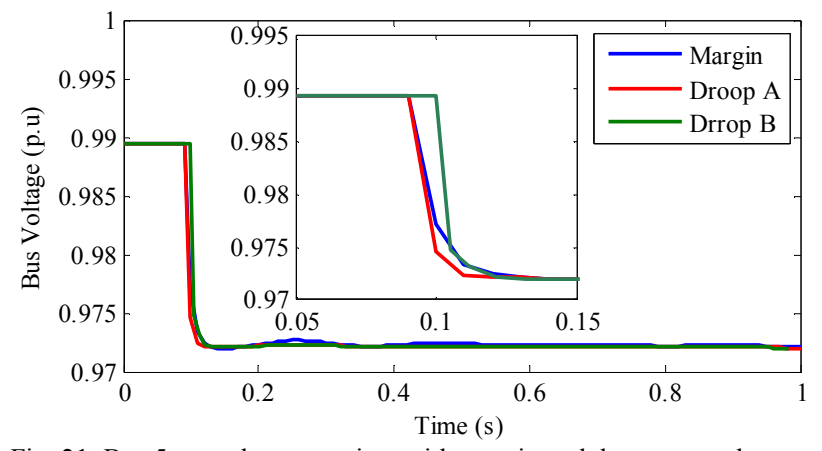

Fig. 21. Bus 5, ac voltage transient with margin and droop control strategies.

TABLE I

SLOPE OF VOLTAGE DROOP CHARACTERISTIC (P.U.)

\begin{tabular}{cccc}
\hline \hline \multicolumn{2}{c}{ Droop $A$} & $\left(-1 / m_{c, i}\right)$ & \multicolumn{2}{c}{ Droop $B$} & $\left(-1 / m_{c, i}\right)$ \\
\hline VSC23 & VSC37 & VSC23 & VSC37 \\
\hline-10.0 & -8.0 & -2.0 & -2.0 \\
\hline
\end{tabular}

Regarding the power load flow, the slack station-converter at bus 3 (VSC37) adapts its power, whereas the power injected by the converter at bus 2 (VSC26) remains unaltered. After a sudden converter-station disconnection, bus voltage at the remaining converter in operation, exhibits a voltage droop which is previously defined by the Droop B characteristic. As shown by the results, the remaining converter powers are both lowered, dictated by their droop characteristics. Simulation shows the voltage margin control is capable to survive a converter outage just if this converter is operating on constant power mode.

\section{CONCLUSIONS}

In this paper, simulation results show the effect of dc Voltage control strategy on the dynamic behavior of bust voltages at multi-terminal HVDC following a converterstation outage. Two different DC voltage control method are simulated in this paper: voltage margin method and voltagedroop method. Time-domain simulations on simple test system using DigSILENT ${ }^{\circledR}$ PowerFactory ${ }^{\mathrm{TM}}$ are used to evaluate the response of ac/dc bus voltage considering two disturbances: sudden load increase and sudden converterstation disconnection. Several scenarios and locations of dc voltage controllers have been considered. Different values of voltage droop slope have been tested showing that the transient response is clearly influenced by the voltage droop characteristic. When two converters on the MTDC operate with dc voltage droop characteristic, it appears a "collaborative scheme" for the dc voltage support, sharing the task of controlling the dc voltage. Simulation results demonstrate the voltage margin control is capable to survive a converter outage just if this converter is operating on constant power mode.

\section{ACKNOWLEDGEMENTS}

The authors gratefully acknowledge the contributions of Mr. Mr. Temesgen M. Haile Selassie from Norwegian University of Technology and Science for his strong supports on $U_{d c}-P$ controllers and Mr. Jef Beerten from the Katholieke
Universiteit Leuven for his support providing data for the dc test case.

\section{REFERENCES}

[1] FOSG. (2011). Friends of the Supergrid. Available: http://www.friendsofthesupergrid.eu/

[2] A. A. Cornago. (2011). Can the European supergrid become reality? Available: http://www.publicserviceeurope.com/article/406/can-theeuropean-supergrid-become-reality

[3] FOSG. (2010). Friends of Supergrind. Position paper on the EC Communication for a European Infrastructure Package. Available: http://www.friendsofthesupergrid.eu/documentation.aspx

[4] T. M. Haileselassie, "Control of Multi-terminal VSC-HVDC Systems," Master of Science in Energy and Environment, Department of Electrical Power Engineering, Norwegian University of Science and Technology, Trondheim Norway, 2008.

[5] T. K. Vrana, R. E. Torres-Olguin, B. Liu, and T. M. Haileselassie, "The North Sea Super Grid - a technical perspective," in $A C$ and DC Power Transmission, 2010. ACDC. 9th IET International Conference on, 2010, pp. 1-5.

[6] D. Van Hertem, M. Ghandhari, and M. Delimar, "Technical limitations towards a SuperGrid: A European prospective," in Energy Conference and Exhibition (EnergyCon), 2010 IEEE International, 2010, pp. 302 309.

[7] D. Van Hertem and M. Ghandhari, "Multi-terminal VSC HVDC for the European supergrid: Obstacles," Renewable and Sustainable Energy Reviews, vol. 14, pp. 3156-3163, 2010.

[8] J. Zhu and C. Booth, "Future multi-terminal HVDC transmission systems using Voltage source converters " presented at the 45th International Universities Power Engineering Conference (UPEC), 2010 Cardiff, Wales 2010

[9] T. Nakajima and S. Irokawa, "A control system for HVDC transmission by voltage sourced converters," in Power Engineering Society Summer Meeting, 1999. IEEE, 1999, pp. 1113-1119 vol.2.

[10] N. Seki, "Field testing of 53 MVA three-terminal DC link between power system using GTO converters," in IEEE Power Engineering Society Winter Meeting, 2000 2000, pp. 2504-2508,

[11] J. Wang, X. Li, and X. Qiu, "Power system research on distributed generation penetration," Automation of Electric Power System, vol. 29, pp. 97-99, 2005.

[12] C. Ismunandar, "Control of Multi-Terminal VSC-HVDC for Offshore Wind Power Integration," M.Sc. thesis, Department of Electrical Sustainable Energy, Delft University of Technology, 2010. 